\title{
O HORIZONTE
}

\section{VALORATIVO}

\section{EM ENUNCIADOS}

DO GÊNERO

\section{COMENTÁRIO ONLINE: UMA ESCUTA}

DIALÓGICA ${ }^{1}$

\section{EL HORIZONTE DE EVALUACIÓN ESTABLECE LA REVISIÓN DE GÉNERO EN LÍNEA: UNA ESCUCHA DIALÓGICA}

\author{
THE EVALUATIVE HORIZON IN UTTERANCES OF THE ONLINE COMMENT GENRE: A \\ DIALOGIC LISTENING
}

Maria de Lourdes Rossi Remenche*

Nívea Rohling**

Universidade Tecnológica Federal do Paraná/Campus Curitiba

\begin{abstract}
RESUMO: Neste artigo é apresentada uma análise de enunciados do gênero comentário online, produzidos/gerados a partir de evento específico, a saber: a greve dos professores da rede pública estadual de ensino do estado do Paraná em 2015. Buscou-se observar os modos como o horizonte axiológico/valorativo se materializa nos comentários online quando é tematizada a identidade profissional docente. Assim, o enfoque do estudo centrou-se no horizonte apreciativo de enunciados que contribuem para os modos sociais de discursivizar o sujeito-professor em momentos de crise político-ideológico - como é uma situação de greve. A análise ancorou-se teórica e metodologicamente nos escritos do Círculo de Bakhtin (BAKHTIN, 2003[1979]; 2015[1975]; VOLOCHÍNOV, 2013[1930]). Os resultados mostram que, em determinados enunciados, o professor é discursivizado como uma

\footnotetext{
${ }^{1}$ Este texto é resultado das ações de pesquisa do Grupo de Pesquisa em Linguística Aplicada (GRUPLA) da Universidade Tecnológica Federal do Paraná/Campus Curitiba.

* Professora Adjunta do Departamento Acadêmico de Linguagem e Comunicação, da Universidade Tecnológica Federal do ParanálCampus Curitiba. Doutora em Linguística pela Universidade de São Paulo/USP. E-mail: mremenche@utfpr.edu.br

** Doutora em Linguística pela Universidade Federal de Santa Catarina. Docente do Programa de Pós-Graduaça em Estudos de Linguagens do Departamento Acadêmico de Linguagem e Comunicação, da Universidade Tecnológica Federal doParaná/CampusCuritiba.E-mail: niveajoi@yahoo.com.br.
} 
categoria abstrata em que o sujeito é descorporificado no discurso, sendo considerando um "fantoche" das relações materiais e sociais. Em outros, buscam-se elementos no ato ético do professor, na sua relação com seu outro ou outros, alunos, pais e comunidade escolar para julgá-lo como alguém sem compromisso com seus pares. No entanto, há também vozes dissonantes que desestabilizam os discursos depreciativos reenunciados.

PALAVRAS-CHAVE: Gênero comentário online. Horizonte valorativo. Círculo de Bakhtin.

RESUMEN: Este artículo presenta un análisis de enunciados del género comentario en línea, producidos/generados a partir de evento específico, a saber: la huelga de los profesores de las escuelas públicas del estado de Paraná en 2015. Se han observado las formas como el horizonte de evaluación axiológico se materializa en los comentarios en línea, cuando se tematiza la identidad profesional docente. Así que el planteamiento del estudio es el horizonte apreciativo de enunciados que contribuyen a los modos sociales de enunciar el sujeto-profesor en momentos de crisis política e ideológica - como en una situación de huelga. Se ha anclado el análisis teórico y metodológico en los escritos del Círculo de Bajtín (BAKHTIN, 2003[1979]; 2015[1975]; VOLOCHÍNOV, 2013[1930]. Los resultados muestran que, en determinados enunciados, el profesor está enunciado como una categoría abstracta en que el sujeto está sin cuerpo en el discurso, como un "títere" de las relaciones materiales y sociales. En otros, hay una búsqueda de elementos en el acto ético del profesor - en su relación con el otro o otros -, los estudiantes, padres y la comunidad escolar, para juzgarlo como alguien sin compromiso con sus compañeros. Sin embargo, también hay voces discrepantes, que desestabilizan los discursos despectivos reenunciados.

PALABRAS CLAVE: Género comentario en línea. Horizonte valorativo. Círculo de Bajtín.

ABSTRACT: In this article we present an analysis of utterances of the online comment genre produced/generated from a specific event: the strike that took place in 2015 headed by teachers from the public school system of the state of Paraná. We aimed at observing how the axiological/evaluative horizon is materialized in online comments, when the identity of a teaching professional is thematized. With that, the focus of this study was the appreciative horizon of utterances that contribute to social modes of creating discourse about the subject-teacher in moments of political and ideological crisis - such as strikes. The analysis was theoretical and methodological, anchored in the writings of Bakhtin's Circle (BAKHTIN, 2003[1979]; 2015[1975]; VOLOCHÍNOV, 2013[1930]). The results prove that, in some utterances, the discourse about the teacher puts him/her in an abstract category in which the subject is disembodied in the discourse, thus being considered a "puppet" of material and social relationships. In others, elements are searched in the teacher's ethical act - in his/her relationship with the other or others - students, parents, and school community ready to place judgment on the teacher as someone who is uncompromised with the peers. However, there are also dissonant voices that destabilize the derogatory discourses that are re-uttered.

KEYWORDS: Online-comment genre. Evaluative perspective. Bakhtin Circle.

Dê uma máscara ao homem e ele dirá a verdade. (Oscar Wilde)

\section{INTRODUÇÃO}

Contemporaneamente o espaço digital tem sido um lócus produtivo de construção de subjetividades, no qual os sujeitos se põem a falar sobre si e sobre os acontecimentos da atualidade de forma mais fluida. De modo mais específico, os comentários publicados na mídia digital, mais precisamente na esfera do jornalismo, operam como construções socioideológicas em grande escala, ao avaliar e validar os discursos já-ditos; ao tornar público o que é privado; ao impor acento de valor sobre objetos discursivos que vão desde acontecimentos sociais até aspectos pessoais e profissionais das pessoas. Nesse espaço sociocomunicativo, evidencia-se, de modo mais saliente, a valoração axiológica nos enunciados proferidos pelos sujeitos.

Inserido nesse contexto heterodiscursivo, este artigo apresenta uma análise de enunciados do gênero comentário online, postados no jornalismo digital tendo como horizonte temático a greve dos professores da rede pública estadual do Paraná em 2015. O objetivo da investigação foi observar e analisar o horizonte axiológico/valorativo desses enunciados no tocante à identidade docente dos

Remenche \& Rohling $\mid$ O horizonte valorativo em enunciados do gênero comentário online.. 
professores da educação pública. Em outros termos, perceber os tons/gestos apreciativos que contribuem para os modos sociais de compreender e discursivizar o sujeito-professor em momentos de crise político-ideológico, como é um movimento de greve.

A disposição em analisar tais enunciados se deu pela emergência de problematizar tais discursos e pensar novos modos de compreender o trabalho do professor o que tem relação com os estudos sobre a identidade ${ }^{2}$ docente, evidenciando como, em usos particulares da linguagem, construímos significados sobre o que é ser professor hoje na escola pública. Kleiman et al. (2013), há tempos chama a atenção para a necessidade de estudos que focalizem a identidade do professor construída nas mais variadas interações sociocomunicativas. Tal investigação busca analisar mecanismos enunciativo-discursivos que sustentam posicionamentos valorativos e estereótipos relacionados à identidade dos professores, um grupo que historicamente está à margem do poder. Segundo Kleiman et al.(2013), tais pesquisas possibilitam compreender a multiplicidade de identidades com as quais os sujeitos se identificam ou não, e mostrar como professores constroem suas posições discursivas frente às vozes sociais que, com frequência, os desvalorizam profissionalmente.

Para tanto, inicialmente, fazemos uma discussão teórica sobre a noção de horizonte axiológico/apreciativo a partir dos escritos do Círculo de Bakhtin e, na sequência, apresentamos uma descrição panorâmica do gênero comentário online. Em seguida, detalhamos os aspectos metodológicos imbricados no estudo e, por fim, evidenciamos as regularidades observadas no processo de análise dos dados.

\section{A DIMENSÃO VALORATIVA/AXIOLÓGICA NOS ENUNCIADOS CONCRETOS}

No construto teórico do Círculo de Bakhtin³ , destaca-se a noção de axiologia/valoração, uma vez que toda enunciação é dialógica e axiológica por natureza. Volochínov (2013, p. 169) chama de orientação social do enunciado a dependência do peso sóciohierárquico do auditório - pertencimento de classe dos interlocutores, a condição econômica, profissional etc. A orientação social é uma das forças vivas e organizadoras dos enunciados (VOLOCHÍNOV, 2013, p. 169).

O enunciado é constituído de uma parte verbal (semiótica) e uma extraverbal, que se relaciona com a situação de interação, em outras palavras, as condições de produção e circulação do enunciado. É a diferença de situações de produção do enunciado que determina a diferença de sentidos de uma mesma expressão verbal (VOLOCHÍNOV, 2013).

Segundo Volochínov (2013), a parte extraverbal se compõe do horizonte espacial e temporal (o onde e quando); o horizonte temático (de que trata a enunciação) e o horizonte valorativo que é a atitude/valoração dos falantes. É importante, porém, ressaltar que tais dimensões são observadas de modo separado para fins metodológicos, mas estão intimamente imbricadas na materialidade dos enunciados concretos, pois o enunciado efetivo/produzido está ligado à situação interlocutiva: espaço-tempo e tema do enunciado; de que falam, quando e em que espaço social de uso da linguagem.

Desse modo, não há enunciado sem a dimensão valorativa ou orientação social. Contudo, também não há valoração sem uma expressão material/sígnica. Assim é que essa dimensão axiológica/valorativa se marca ideologicamente não só na situação de interlocução como também na concretude material-semiótica dos enunciados. Isso, porque, sem uma materialidade, a enunciação não existe. É na materialidade dos enunciados, na forma de enunciação, entonação, seleção e disposição das palavras ou signos mobilizados que se evidencia a dimensão valorativa.

Tal reflexão nos autoriza a relacionar a noção de valorativo/axiológico à de ideologia, tendo em vista que dimensão valorativa é intrínseca aos signos e neles se materializa, pois tudo que é sígnico é ideológico.

\footnotetext{
${ }^{2}$ Neste artigo, as identidades são concebidas como construtos históricos intimamente relacionados às práticas discursivas dos sujeitos. Isso, porque o sujeito está em "[... um movimento contínuo entre o eu e o outro, em que eu vivencio minha vida de dentro e o outro me dá completude exterior, infere-se que os acabamentos e as identidades sempre múltiplas no tempo e no espaço [...]” (GERALDI, 2010, p. 143, grifo do autor).

${ }^{3}$ Indicamos, no corpo do artigo, a edição consultada das obras do Círculo de Bakhtin e, nas referências, mencionamos também o ano da primeira edição das obras citadas.
} 
Para Bakhtin, a língua é saturada ideologicamente, como propõe na citação a seguir:

\begin{abstract}
Não tomamos a língua como um sistema de categorias gramaticais abstratas; tomamos a língua ideologicamente preenchida, a língua enquanto cosmovisão e até como uma opinião concreta que assegura um maximum de compreensão mútua em todos os campos da vida ideológica. (BAKHTIN, 2015, p.40, grifo do autor)
\end{abstract}

Embora a ideologia seja inerente à linguagem, nesse escopo teórico, não pode ser interpretada de modo simplificado como sendo um mascaramento do real ou como uma relação binária entre ideologia dominante e ideologia dominada.

De acordo com Faraco (2013), nos textos do Círculo de Bakhtin, são usados diferentes termos que remetem ao fenômeno da ideologia, tais como: "semântico", "verboideológico", "axiológico", "visão de mundo", "pontos de vista” e "sistemas de crença”. Essas expressões remetem a uma visão de mundo, ou melhor, diferentes versões que os sujeitos históricos e concretos constroem nas suas histórias de vida sobre o mundo (FARACO, 2013). Desse modo, é necessário compreender, nos escritos do Círculo, a ideologia de modo mais alargado, como algo que é constitutivo da linguagem e do sujeito e ligado às diferentes compressões que os sujeitos e grupos sociais constroem do mundo. Isso, porque viver significa ocupar uma posição axiológica em todas as instâncias da vida.

O horizonte valorativo se constitui a partir de índices sociais de valor presentes nos enunciados concretos, que, segundo Bakhtin/Volochínov (2004), são elementos essenciais na constituição do signo ideológico; sem os índices valorativos, o signo nada mais é que uma "alegoria", "objeto de estudo dos filólogos", "signos ideológicos defuntos" (BAKHTIN/VOLOCHÍNOV, 2004, p. 46). Dessa forma, só pode ser considerado signo aquilo que já adquiriu um valor social, tendo em vista que "[...] a cada etapa do desenvolvimento da sociedade, encontram-se grupos de objetos particulares e limitados que se tornam objeto de atenção do corpo social e que, por causa disso, tomam um valor particular" (BAKHTIN/VOLOCHÍNOV, 2004, p. 44). Cada signo constituído possui um tema, que é a realidade que dá lugar à formação de um signo, e o tema, por sua vez, possui sempre um índice de valor social.

Agrega-se ao signo um ponto de vista, uma posição axiológica dos diferentes grupos sociais. Sendo, pois, uma posição axiológica, o signo não só reflete uma realidade, mas também refrata uma outra. Em outros termos, o signo ideológico não é apenas um reflexo, uma sombra da realidade, mas também um fragmento material dessa realidade (BAKHTIN/VOLOCHÍNOV, 2004). Assim, no signo ideológico, confrontam-se índices de valor contraditórios, e é justamente esse entrecruzamento dos índices de valor que torna o signo vivo e móvel. Os índices sociais de valor são responsáveis pela constituição do signo, fazendo com que ele se movimente (SILVA, 2010).

A partir dessas concepções epistemológicas, a seguir, apresentamos uma descrição panorâmica do gênero comentário online.

\title{
3 SOBRE O GÊNERO COMENTÁRIO ONLINE
}

Ao empreender uma análise dialógica do discurso, é preponderante tomar a língua no seu aspecto histórico e concreto, uma vez que o discurso não se constrói sobre uma determinada realidade sem a relação constitutiva e de respondibilidade com outros discursos. Nessa concepção de linguagem, de caráter sócio-histórico, o ponto de partida para a análise de enunciados são, inicialmente, os estratos sociais mais amplos, para então compreender a materialidade verbal-semiótica. O estudo do discurso verbal implica um olhar para as relações dialógicas, pois a linguagem só vive na comunicação dialógica daqueles que a usam (BAKHTIN, 2008).

\footnotetext{
${ }^{4} \mathrm{O}$ artigo não tem como objetivo apresentar uma análise descritiva do gênero comentário online, mas de abordar um aspecto mais pontual, a saber, do horizonte axiológico materializado nesses enunciados. Alves Filho e Santos (2013) e Cunha (2012) apresentam análises mais detalhadas do comentário do ponto de vista de suas regularidades de gênero discursivo.
} 
A partir dessa orientação teórico-metodológica, nesta seção, apresentamos aspectos relacionados à condição de gênero ${ }^{5}$, ou seja, questões ligadas à produção e circulação dos enunciados, tendo em vista que o horizonte valorativo dos grupos socialmente organizados de determinada época integra-se ao signo, produzindo enunciados de gêneros discursivos.

A linguagem corporifica-se/materializa-se por meio de gêneros discursivos, que são constituídos nas diferentes situações de interação social. Bakhtin (2003, p. 293) argumenta que os "[...] gêneros correspondem a situações típicas da comunicação discursiva, a temas típicos, por conseguinte, a alguns contatos típicos dos significados das palavras com a realidade concreta em circunstâncias típicas". Nesse sentido, cada gênero tende a manter uma relativa tipificação em torno do tratamento dado aos conteúdos ideologizados. Infere-se daí que a existência de gênero envolve o compartilhamento não apenas da linguagem, mas também de um conjunto de atividades sociais, mediadas pelos gêneros.

Com relação ao gênero tomado para a presente análise, vale dizer que não se trata de um gênero constituído no meio digital, embora o espaço digital tenha possibilitado um uso mais intenso e frequente (ALVES FILHO; SANTOS, 2013). O gênero comentário online se realiza em diferentes campos de produção e circulação, sendo recorrente em portais de notícias e em redes sociais, constituindose em um espaço interlocutivo, aberto ao leitor/interlocutor para a exposição de opinião, considerando as regras sociais e institucionais inerentes à esfera de produção e circulação. Devido a essa possibilidade de apresentar sua contrapalavra, essa interação sociodiscursiva tende a estimular o desabafo e a explicitação de opiniões e formas de representar o mundo bastante subjetivas, ou seja, os comentários suscitam atitudes responsivas de refutação, desabafo, apoio, indignação, entre outras, e materializam axiologicamente os diferentes valores sociais.

Os comentários não exigem uma sequência cronológica para réplica, o comentador pode responder a qualquer um dos comentários na ordem em que julgar necessário. O leitor pode comentar tanto a notícia quanto outro comentário já expresso sobre ela. Em virtude disso, é comum que uma sequência de comentários, embora mantenha diálogo com a notícia, remeter-se a outros comentários ou, ainda, a elementos externos à notícia. Nesse sentido, Alves Filho e Santos (2013) ressaltam que esse gênero atende a uma necessidade social de manifestação da opinião pública na esfera jornalística, assim como responde a um posicionamento cultural da mídia, que busca estimular a participação responsiva-ativa dos leitores a respeito dos temas veiculados, convidando-os a expor sua contrapalavra e manifestar apreciações e opiniões pessoais no espaço intitulado de comentário.

O comentário online constitui, assim, um discurso-resposta a um acontecimento noticiado ou debatido (no caso de artigos assinados, por exemplo) e, principalmente, a outros comentadores, tendo um interlocutor imediato mais específico (o jornalista/articulista, um outro comentador, um dos envolvidos no acontecimento etc.), mas o seu auditório social é a coletividade de leitores internautas (ALVES FILHO; SANTOS, 2013).

Já Cunha (2012, p. 28) caracteriza o comentário como:

[...] uma prática discursiva que tem seu propósito e suas regras: a partir de um texto fonte, o leitor constrói novos discursos, reacentuando diferentemente os aspectos temáticos, os sentidos múltiplos, explícitos ou subentendidos, ou introduzindo deslocamentos e mudanças de tema.

Do ponto de vista do tema, o gênero comentário online é marcado por tipificação e inovação ao mesmo tempo, visto que apresenta traços recorrentes ao mesmo tempo que apresenta inovação (atualização) em vista dos diferentes acontecimentos sociais comentados e das diferentes situações enunciativas (ALVES FILHO; SANTOS, 2013). Isso aponta para o fato de que o comentário online constitui-se não só do tema do gênero, mas também do tema da enunciação. Segundo Alves Filho e Santos (2013, p. 13):

\footnotetext{
${ }^{5}$ Embora esta seção tenha um caráter mais amplo, em alguns momentos, apresentamos uma discussão mais particularizada a partir dos dados desta pesquisa, sobretudo no tocante ao aspecto da autoria do gênero comentário online.
} 
O tema da enunciação se constitui a partir de cada nova enunciação, ou seja, é o resultado da avaliação apreciativa de um sujeito que ocupa um lugar social único, capaz de particularizar sua resposta. [...] Já o tema do gênero, ao contrário do tema da enunciação, é resultante de uma relativa tipificação no modo como os usuários de um gênero costumam tratar os assuntos num determinado gênero.

Assim, o gênero comentário online possui como tema "[...] o posicionamento axiológico do comentador que defende certa ideia de justiça, colocando-se contra ou a favor dos acontecimentos noticiados” (ALVES FILHO; SANTOS, 2013, p. 13).

No tocante à autoria, destacamos que “[...] todo gênero tem sua própria concepção de autoria” (RODRIGUES, 2001, p.135), que não está relacionada à pessoa física (empírica), mas a uma posição de autoria inscrita no próprio gênero. Nesse sentido, todo gênero estabelece entre seus interlocutores a sua própria concepção de autoria, alguns de forma mais explícita e outros de maneira presumida. De modo geral, consideramos que os enunciados do gênero comentário online, postados pelos interlocutores (leitores de mídia digital), são contrapalavras/projetos de dizer desses sujeitos motivados/disparados pela leitura de uma publicação (notícia, reportagem, artigo assinado etc.).

No entanto, no que se refere especificamente aos dados deste estudo, tendo em vista o grau de tensão do evento em questão marcado inclusive por ações de violência física -, prevemos as possibilidades pragmáticas de que os enunciados analisados possam constituir textos escritos por sujeitos implicados de modo mais direto no evento (cabos eleitorais/representantes governamentais, partidários políticos, pais, professores etc.). O que implica considerar como motivação discursiva para produção desses enunciados não somente a notícia publicada pelo jornal, mas também uma situação social mais emblemática relacionada às relações de poder que envolvem um movimento de greve.

Assim, assumimos a possibilidade de serem escritas afetadas por jogos de poder, uma vez que se tratam de comentários em resposta a matérias jornalísticas que tematizam a greve a partir do horizonte valorativo de uma empresa que revelou, nas próprias notícias publicadas, certo alinhamento ao discurso governamental (discurso oficial) sobre a greve. Apesar desse cenário político-ideológico em que foram produzidos esses enunciados, no âmbito de uma pesquisa dialógica, é preciso considerar tanto a dimensão extraverbal como a própria produção discursiva na sua materialidade linguageira-semiótica. Desse modo, nos propomos a analisar discursos em circulação, que ecoam e transitam na esfera jornalística-midiática e que, de algum modo, têm ressonância na (re)construção da identidade e profissionalidade docente.

Diante disso, neste artigo, partimos da acepção bakhtiniana de autoria como assinatura e acabamento discursivo-estilístico. Bakhtin (2003, p. 308) afirma que todo “[...] texto tem um sujeito, um autor (o falante, ou quem escreve)"; não "[...] há palavra sem dono [...]" (2003, p. 328). Ou, ainda, que na “[...] relação criadora com a língua não existem palavras sem voz, palavras de ninguém. Em cada palavra há vozes às vezes infinitamente distantes, anônimas, quase impessoais [...] e vozes próximas [...]”. (BAKHTIN, 2003, p. 330).

Tendo em vista que o autor de um enunciado é aquele que assina e dá acabamento para seu dizer, como delinear então a autoria no gênero comentário online nos enunciados aqui analisados?

A evidência de autoria, no comentário online, está intimamente relacionada a própria condição do gênero constituído no espaço digital. Em comparação ao gênero carta do leitor, por exemplo, observamos que o autor-leitor deste gênero precisa se mostrar mais, é requerido a ele uma identificação e uma responsabilização pelo seu dizer ${ }^{6}$. Já no caso do comentário online, por sua acessibilidade e modo breve, o autor pode evidenciar a autoria por meio de uma "máscara”. Ou seja, usar um outro; um nickname, uma espécie de avatar que resguarda/oculta, de certo modo, o sujeito empírico. Vale lembrar que a função da máscara no teatro era ocultar a face do artista, embora, ao final do espetáculo, a máscara fosse retirada. No comentário, ao contrário, a máscara se mantém e serve como forma de encorajamento ao sujeito para realizar projetos de dizer que não faria sem a "proteção" dessa máscara. Projetos de dizer que, muitas vezes, não medem os impactos e as consequências éticas dessa palavra. Eé justamente essa possibilidade de ocultamento do sujeito empírico que possibilita um tom mais agressivo, menos polido, mais diretivo e incisivo nos enunciados.

${ }^{6}$ Na produção de carta do leitor, a empresa jornalística solicita, muitas vezes, que o autor declare o seu nome completo e documentos pessoais, além de ser enviado pelo e-mail pessoal do autor da carta. 
Então, para empreender a análise proposta, partimos da noção de que os enunciados recebem uma assinatura; há um autor declarado nos textos. Mesmo levando em conta que os sujeitos criam avatares para seu dizer, nosso foco recai sobre a valoração axiológica no discurso que está circulando e se materializando nesse gênero específico. Em outras palavras, são focalizados os discursos/vozes sociais em circulação sobre a identidade profissional do professor que precisam ser problematizados.

Na seção seguinte, apresentamos, de modo mais pontual, as especificidades metodológicas da pesquisa.

\section{PERCURSO METODOLÓGICO}

Como dito antes, neste estudo, tomamos como base epistêmica e metodológica a concepção bakhtiniana de linguagem, de discurso, de enunciado e de valoração axiológica (BAKHTIN, 1998, 2003, 2015; BAKHTIN/VOLOCHÍNOV, 2004; VOLOCHÍNOV, 2013).

A delimitação do tema da pesquisa - horizonte axiológico de enunciados do gênero comentário online - foi motivada pelo intenso debate público em diferentes esferas de atividade humana (política, midiática, jornalística e cotidiana) sobre os acontecimentos engendrados em um evento específico, a saber: a greve dos professores da rede pública estadual de ensino do estado do Paraná em 2015 .

Consideramos o movimento de greve como uma arena discursiva e, nessa condição, como propõem Guimarães e Queijo (2015) ${ }^{7}$, esse evento constitui-se em espaço de disputa e de luta que projeta um caráter de tensão entre o discurso oficial e o não oficial, produzindo discursos contraditórios.

Como amplamente noticiado em todo país na ocasião, o movimento de greve dos professores do Paraná em 2015 foi extenso (durou 44 dias) e marcado por violência física por parte do sistema governamental e policial em relação aos servidores públicos estaduais. A greve teve seu ponto culminante, o dia 29 de abril de 2015, quando ocorreu uma exacerbada ação policial contra os professores, em Curitiba (PR). Nesse dia, ocorreu uma manifestação de servidores públicos estaduais que se opunham à votação, na Assembleia Legislativa do Estado, de um projeto de lei que propunha mudanças no custeio do regime de previdência dos servidores. A ação truculenta por parte da polícia militar do Estado, que feriu cerca de 200 pessoas presentes na manifestação, repercutiu nas mídias nacionais, causando uma comoção pública e suscitando uma série de posicionamentos/reações e resposta ativa em relação ao tema.

Nesse contexto tenso e de embate ideológico, foram produzidos vários enunciados jornalísticos (notícias, artigos assinados, entrevistas) que emergem "[...] como atitude avaliativo-responsiva a acontecimentos atuais, tidos como verídicos e de interesse coletivo" (ALVES FILHO; SANTOS, 2013, p. 7), tendo como objeto de discurso a greve dos professores do Paraná e seus desdobramentos, dentre eles, as notícias que geraram os comentários aqui analisados.

Assim, foram selecionados 18 (dezoito) enunciados do gênero comentário online acerca de três notícias publicadas no período de março a junho de 2015, no portal do jornal Gazeta do Povo. As notícias, bem como os comentários, possuem uma relativa tipificação em torno do tema recorrente - greve dos professores da rede pública.

A seguir, o quadro 1 apresenta um detalhamento dos dados 8 .

\footnotetext{
${ }^{7}$ Adotamos a noção de arena discursiva, proposta por Guimarães e Queijo (2015), a partir da análise de enunciados de cartazes das manifestações de rua ocorridas em 2013, no Brasil.

${ }^{8}$ Os enunciados são apresentados, neste texto, sem correção ou edição. No decorrer da análise, usamos N para apontar a notícia que deu origem ao enunciado de comentário; usamos C para remeter ao comentário em análise.
} 
Quadro 1: Título das notícias e seleção de comentários online relacionados

\begin{tabular}{|c|c|c|}
\hline $\begin{array}{c}\mathrm{N} 1 \\
\text { Greve dos professores tem apoio de } \\
90 \% \text { dos paranaenses } \\
(03.03 .2015)\end{array}$ & $\begin{array}{l}\mathrm{N} 2 \\
\text { A greve dos professores }{ }^{10}(10.05 .2015)\end{array}$ & $\begin{array}{c}\mathrm{N} 3 \\
\text { Em assembleia, professores encerram a } \\
\text { greve da categoria }{ }^{11}(09.06 .2015)\end{array}$ \\
\hline $\begin{array}{c}\text { Cl } \\
\text { Mentira. Só aqui no bairro muito mais } \\
\text { que } 10 \% \text { nao apoiam esses marxistas } \\
\text { baderneiros. }\end{array}$ & $\begin{array}{c}\text { Cl } \\
\text { O povo paranaense não quer pagar quem não trabalha. O } \\
\text { povo já percebeu a enrolação e a falta de vontade desse povo } \\
\text { voltar a trabalhar. Querem ficar em férias ganhando sem } \\
\text { trabalhar. Vergonha!!! }\end{array}$ & $\begin{array}{c}\text { Cl } \\
\text { Vamos trabalhar PTzada!!! Se um } \\
\text { trabalhador ficar em casa por que quer } \\
\text { aumento, ele não recebe e tem os dias } \\
\text { descontados e pode perder o emprego se for } \\
\text { configurado o abandono de função, Os } \\
\text { professores não estão nem aí para os alunos } \\
\text { que estão com o ano letivo ferrado, e ainda } \\
\text { querem receber pelos dias NÃO } \\
\text { trabalhados. A reivindicação dos } \\
\text { professores é justa, mas essa greve já passou } \\
\text { dos limites, estão pouco se lixando para as } \\
\text { crianças. }\end{array}$ \\
\hline $\begin{array}{l}\text { C2 } \\
\text { Nos orgulha muito a iniciativa, a bravura } \\
\text { e a persistência dos nobres professores } \\
\text { no seu pleito diante de um governo } \\
\text { irresponsável e mais ainda incompetente } \\
\text { que temos nos últimos anos. Parabéns, e } \\
\text { continuem na luta que acredito que será } \\
\text { vencedora e em breve!! FORÇA } \\
\text { NOBRES PROFESSORES!!! }\end{array}$ & $\begin{array}{l}\text { C2 } \\
\text { Gostaria de fazer uma pergunta, não precisa me chamar de } \\
\text { ignorante não, eu não sei mesmo, professor bate cartão? } \\
\text { Ponto eletrônico ? Passa o dedinho no ponto biométrico ?É } \\
\text { uma curiosidade que me surgiu de tanto ler sobre eles. }\end{array}$ & $\begin{array}{l}\text { C2 } \\
\text { Uma tragédia para a educação no Paraná. } \\
\text { Nunca na História de um estado da } \\
\text { federação tantos foram prejudicados por } \\
\text { tão poucos. Crianças que eram pra estar na } \\
\text { sala de aula estão morrendo atropeladas nas } \\
\text { rodovias. Tudo porque alguns, massa de } \\
\text { manobra de partido corrupto, só pensam } \\
\text { no bolso. }\end{array}$ \\
\hline $\begin{array}{c}\text { C3 } \\
\text { quem fez esta pesquisa e com quem? Há } \\
45 \text { anos, ano após ano, professor é aquele }\end{array}$ & C3 & C3 \\
\hline
\end{tabular}

profissional que está de greve ou está saindo de uma greve ou está entrando numa greve. Porque os professores vocacionados gostam de dar aula e um bando de aproveitadores assume $o$ sindicato. Professor tem direito a greve e o povo tem direito não só ao recebimento das aulas mas também tem o direito de exigir que o Governo não use o dinheiro do contribuinte que trabalha para pagar dias parados de grevistas crônicos. Pais estão entrando pedindo indenização JUDICIAL contra a APP e membros da DIretoria.

\section{C4}

o povo paranaense se orgulha e muito dos professores Paraná e acho que a única opinião comprada aqui são esses
Ridículo este aparelhamento comunista da mídia. Essa invasão foi orquestrada pelo PT e PSOL para abafar os escândalos federais, inclusive com presença da Gleise/PT, que é investigada pela Lava-Jato, cuja sede de operações é no Paraná. Os professores foram apenas massa de manobra numa tentativa ridícula de "reocupar as ruas" (conforme documento do próprio PT já previa) por meio da violência e vandalismo, se fossem apenas professores protestando não teríamos feridos. A propósito, sou contra o governador de qualquer maneira, mas queria deixar claro que não aceito ser manipulado por vocês petistas
Os professores espernearam, entraram em surto e foram à greve. Mas não gostam que o governo revele que o salário médio dos professores estaduais do Paraná é acima de R\$ 4,5 mil para 40 horas/aulas. Essa greve foi meramente politiqueira e agora temos que ficar na torcida que os professores alienados a APP-Sindicato que nada mais é do que um braço do PT e realmente comecem a dar uma aula de qualidade.

\section{$\mathrm{C} 4$}

Para que a educação não fique refém dessa gente descompromissada, que olha só para o próprio umbigo e esquece dos alunos, deve ser privatizada. O Ensino Médio

\section{$\mathrm{C} 4$}

agora que finalmente essa palhaçada toda acabou, que possamos ver nossos alunos com ensino de qualidade, afinal de contas é 


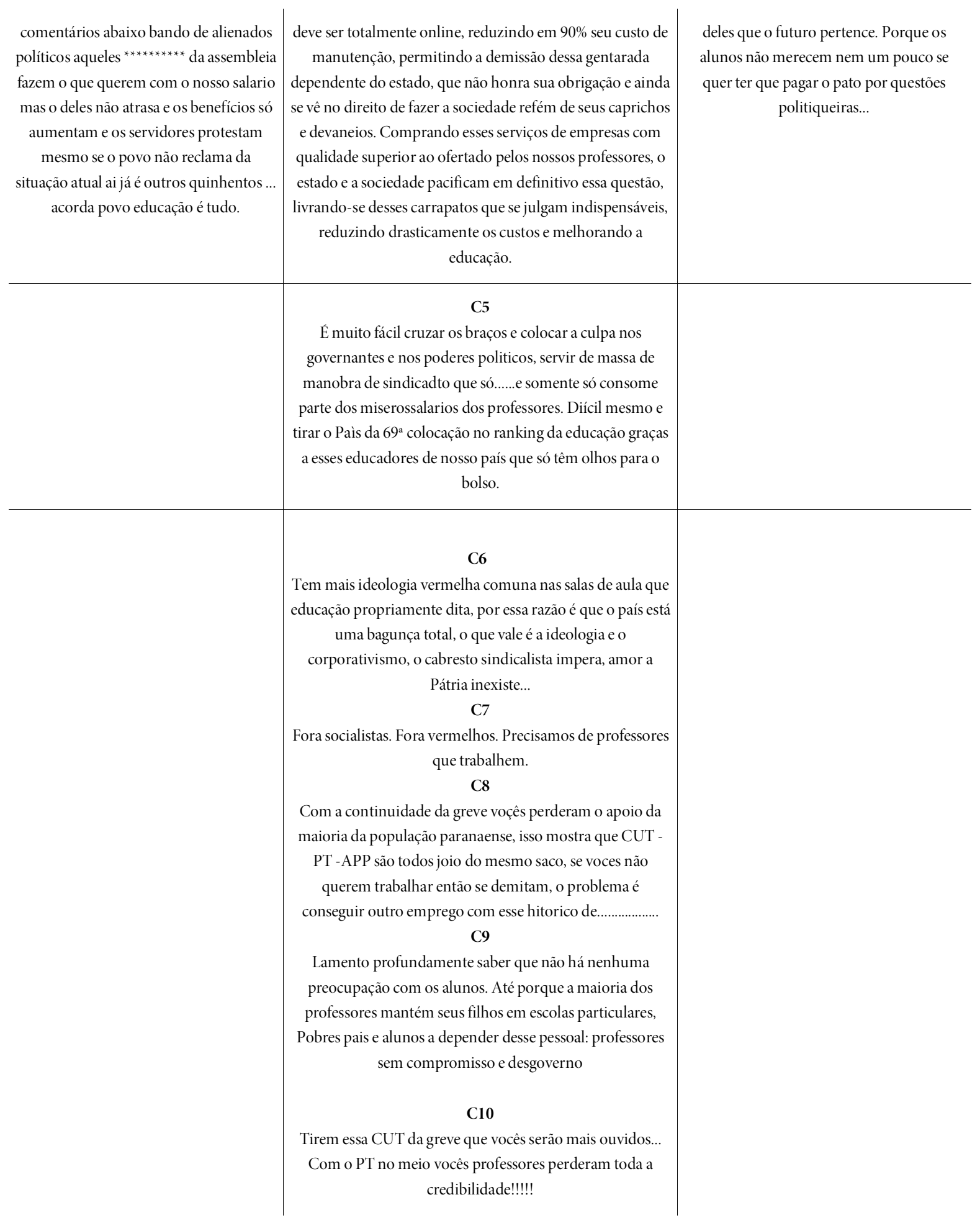

Fonte: as autoras (2015)

De modo geral, no tocante ao conteúdo temático, mais especificamente à relação entre os comentários e as notícias geradoras desses enunciados, o espaço temporal delimitado (março a junho de 2015) põe em evidência uma regularidade do gênero comentário online que é a possibilidade de resposta a outro comentário. Ainda que a notícia seja o evento deflagrador da sequência, constituindo-se como eixo de produção do gênero, muitos comentários não replicam/respondem à notícia, mas sim a outros comentários. A análise evidencia que, nos comentários registrados a respeito das três notícias em foco, houve um deslocamento da notícia para um segundo plano, abrindo espaço para um diálogo entre os próprios comentadores. Essa dinâmica produz uma rede discursiva bastante singular, pois, como já mencionado anteriormente, embora o comentário online surja a partir de um incentivo do portal jornalístico, que destina um espaço aos leitores para comentarem a notícia, esse propósito inicial acaba por ser 
minimizado, uma vez que a notícia é, de certa forma, deixada de lado, cedendo espaço para um diálogo entre os próprios comentadores (ALVES FILHO; SANTOS, 2013, p. 85). Essa dialogicidade interna do gênero pode ser observada a seguir:

\begin{abstract}
N1C4
o povo paranaense se orgulha e muito dos professores Paraná e acho que a única opinião comprada aqui são esses comentários abaixo bando de alienados politicos aqueles ${ }^{* * * * * * * * *}$ da assembleia fazem o que querem com o nosso salario mas o deles não atrasa e os benefícios só aumentam e os servidores protestam mesmo se o povo não reclama da situação atual ai jáé outros quinhentos ... acorda povo educaçãoétudo.
\end{abstract}

A análise dos comentários revela ainda um acento valorativo que faz com que uma mesma palavra, sempre que reenunciada na trama das interações, tenha um acento de valor de conteúdo ideologizado, que é atravessado valorativamente pelas entoações relativas à greve e aos acontecimentos implicados. Verifica-se também o uso de recursos multimodais que evidenciam a intenção discursiva do enunciado para desqualificar os sujeitos aos quais se referem como, por exemplo, o uso de diversos asteriscos para nomear as "pessoas da assembleia", preenchendo o não dito de possibilidades de sentido negativo. Aqui evidencia-se uma acentuação valorativa, isso porque, de acordo com Bakhtin (2004, p. 140), "[...] não se pode construir uma enunciação sem modalidade apreciativa. [...] Toda enunciação compreende antes de mais nada uma orientação apreciativa.”. Nesse contexto discursivo, a atualização do tema da enunciação nos diferentes comentários ocorre a cada nova réplica (comentário), afinal o conteúdo ideologizado é de natureza social e individual ao mesmo tempo, pois se constitui tanto pelas relações sociais, quanto pelo ethos do indivíduo, que imprime ao tema da enunciação um caráter de unicidade.

A seguir apresentamos a análise mais pontual da expressividade dos enunciados, que se revela na materialidade linguageira.

\title{
5 O HORIZONTE AXIOLÓGICO NOS ENUNCIADOS DO GÊNERO COMENTÁRIO ONLINE
}

A análise das marcas linguageiras/estilísticas mais específicas nos enunciados em tela se deu pela observação de posições axiológicas e das relações dialógicas que apontam para a assimilação de discursos já-ditos e discursos prefigurados (reação resposta antecipada), discursos bivocais, apagamentos de sentidos, contraposições, enquadramentos, reenunciação de discursos e reacentuações de discursos em relação ao objeto discursivizado nos enunciados.

Como é próprio do gênero, o horizonte valorativo se mostra saliente nos enunciados, sobretudo no tom/acento no modo de referenciar o objeto discursivo. Essa valoração não se manifesta tão somente nos "assuntos" abordados, mostra-se também no acabamento estilístico-composicional, que se materializa no léxico escolhido para fazer referência ao objeto de discurso (marxistas baderneiros, massa de manobra, PTzada). Essas palavras remetem ao modo como o objeto do discurso é tematizado, pois são objetos avaliados, reacentuados e contestados, pois "[...] todo discurso concreto (enunciação) encontra aquele objeto para o qual está voltado sempre, por assim dizer, já desacreditado, contestado, avaliado, [...] iluminado pelos discursos de outrem que falaram sobre ele" (BAKHTIN, 1998, p. 86).

Assim, o professor e o movimento de greve constituem-se objeto do discurso nos comentários, e por isso a valoração axiológica se sobressai, uma vez que esse objeto é envolvido em um "fundo" aperceptivo dos discursos alheios. Segundo Bakhtin (1998, p. 86), o objeto [neste caso, o professor em movimento de greve] “[...] está amarrado e penetrado por idéias gerais, por pontos de vista, por apreciações de outros e por entonações".

A valoração acentuada nos enunciados endereçada ao professor concretiza-se por meio de seu papel social, validado pelas "opiniões" sociais, e pelos já-ditos sobre esse objeto (sujeito-professor). Trata-se de discursos "outros" sobre o objeto do discurso, cujas ressonâncias ideológicas se tornam intensas e "tensas" ou, ainda, trata-se de "[...] discursos já povoados pelas intenções sociais de outrem, obrigando-os a servir às suas novas intenções, a servir ao seu segundo senhor” (BAKHTIN, 1998, p.105)

De modo geral, nos enunciados analisados, o professor é tomado como objeto de discurso, e somente em dois textos o professor é tomado como interlocutor de modo mais diretivo. 
Nos enunciados a seguir, os autores dos comentários enunciam-se de modo diretivo ao professor, tomando os professores envolvidos no movimento como seus interlocutores mais imediatos:

\section{$\mathrm{N} 2 \mathrm{C} 10$}

Tirem essa CUT da greve que vocês serão mais ouvidos... Com o PT no meio vocês professores perderam toda a credibilidade!!!!!

\section{$\mathrm{N} 2 \mathrm{C} 8$}

com a continuidade da greve voçes perderam o apoio da maioria da população paranaense, isso mostra que CUT PT -APP são todos joio do mesmo saco, se voces não querem trabalhar então se demitam, o problema é conseguir outro emprego com esse hitorico de.

Embora a maioria dos enunciados coloquem o professor como tema, os comentários $\mathrm{N} 2 \mathrm{C} 10$ e $\mathrm{N} 2 \mathrm{C} 8$ apresentam uma fala diretiva ao professor, com o uso do pronome de tratamento você que conota um grau de intimidade, explicitando um tratamento de igual para igual ou de superior para inferior. A partir da teoria dialógica, concebemos que, em todos os enunciados em análise, o professor é também interlocutor previsto. Contudo, os enunciados de acusação, de responsabilização ou também de apoio são a ele endereçados, configurando-o, ao mesmo tempo, objeto do discurso sobre o qual recai a orientação apreciativa.

De modo geral, o professor foi discursivizado na condição de categoria, trata-se de falar para uma classe abstrata e essa palavra se mostrou marcada por um tom de depreciação valorativa como mostramos a seguir.

A análise dos comentários revela que essa valoração se materializou de modos distintos. A primeira regularidade nessa orientação valorativa depreciativa foi um discurso que avalia o professor como alguém que não quer trabalhar e o movimento de greve é discursivizado como um espaço de "vadiagem", como mostram os enunciados que se seguem:

\section{$\mathrm{N} 2 \mathrm{C} 2$}

O povo paranaense não quer pagar quem não trabalha. O povo já percebeu a enrolação e a falta de vontade desse povo voltar a trabalhar. Querem ficar em férias ganhando sem trabalhar. Vergonha!!!

\section{$\mathrm{N} 3 \mathrm{C} 2$}

Ninguém ganhará sem trabalhar? Bem.. em certo sentido você tem razão, pois já ganharam 4 meses sem trabalhar. Se não vierem com palhaçada atéo fim do ano novamente, pode ser que daqui pra frente justifiquemo salário. Quer trabalhar para o Governo? Segura a onda agora, meи amigo. Quer ter Governador de patrão? Segura a onda! Quer ganhar mais como professor? Vai pro regime privado, simples assim... quer dizer, no regime privado tem que trabalhar né... talvez não seja tão simples pra vocês... Faz o seguinte, continua balançando bandeira e dizendo que é professor. Me engana que eu gosto..

\section{N2C7}

Fora socialistas. Fora vermelhos. Precisamos de professores que trabalhem.

No comentário N2C2, o enunciador se distancia valorativamente do objeto a partir dos modos de referenciá-lo ("esse povo" "querem [os professores] ficar em férias). Na escolha lexical (esse povo; eles) há um movimento de afastamento e de depreciação da categoria profissional para materializar o seu posicionamento.

Já no comentário $\mathrm{N} 3 \mathrm{C} 2$, o discurso depreciativo que acusa o professor de não querer trabalhar se realiza por meios estilísticos mais sofisticados. Isso se faz na interlocução com o leitor por meio de questionamentos que percorrem o senso comum em relação ao fato de que a remuneração salarial está vinculada ao trabalho e à ideia de segurança do serviço público que pode gerar acomodações e letargias profissionais. Esse discurso recorrente e depreciativo em relação ao serviço público, situa-o como um lugar menos produtivo em relação às instituições privadas (Quer ganhar mais como professor? Vai pro regime privado, simples assim... quer dizer, no regime privado tem que trabalhar né...). O uso de vários pontos de exclamação $(\mathrm{N} 2 \mathrm{C} 1)$ e de reticências por três vezes no 
comentário N3C2 produz efeitos de sentido de indignação, suspensão do pensamento de quem fala, representando a posição axiológica de quem elabora o discurso e, ao mesmo tempo, é um movimento de diálogo com o leitor para que ele elabore a sua réplica.

No N2C7, o último período do enunciado (Precisamos de professores que trabalhem.) possibilita inferir que os professores grevistas não trabalham, por isso se faz necessária a substituição por outros sujeitos com posicionamento político distinto. O uso recorrente do imperativo 'fora' revela também uma acentuação valorativa por parte do comentador e aponta para um conflito estabelecido.

Outra estratégia discursiva que se mostrou como regularidade, no processo de construção da valoração depreciativa do objeto do discurso, foi o movimento de associar a ação grevista dos professores a uma manifestação partidária. Os comentadores relacionam o movimento grevista a uma instância maior - sindical ou governamental -, inclusive mencionam partidos políticos considerados "de esquerda" e instituições sindicais (PT, PSOL, CUT). Desse modo, desconstroem/negam a possibilidade de os sujeitos atuarem em um movimento em prol da sua própria profissionalidade e da melhoria da educação pública. Embora haja variados interesses ideológicos e políticos imbricados a um evento como esse (movimento de greve), não podemos abstrair totalmente o sujeito de seu ato responsável (BAKHTIN, 2010).

A seguir, apresentamos exemplos de enunciados que apontam para essa descorporificação do sujeito no discurso e o prendem a uma estrutura política e ideológica, considerando-o um "fantoche" das relações materiais e sociais.

\section{N1C1}

Mentira. Só aqui no bairro muito mais que 10\% nao apoiam esses marxistas baderneiros.

\section{N2C3}

Ridículo este aparelhamento comunista da mídia. Essa invasão foi orquestrada pelo PT e PSOL para abafar os escândalos federais, inclusive com presença da Gleise/PT, que é investigada pela Lava-Jato, cuja sede de operações é no Paraná. Os professores foram apenas massa de manobra numa tentativa ridícula de "reocupar as ruas" (conforme documento do próprio PT já previa) por meio da violência e vandalismo, se fossem apenas professores protestando não teríamos feridos. A propósito, sou contra o governador de qualquer maneira, mas queria deixar claro que não aceito ser manipulado por vocês petistas

\section{N2C5}

É muito fácil cruzar os braços e colocar a culpa nos governantes e nos poderes politicos, servir de massa de manobra de sindicadto que só......e somente só consome parte dos miserossalarios dos professores. Dí́cil mesmo e tirar o Pais da $69^{a}$ colocação no ranking da educação graças a esses educadores de nosso país que só têm olhos para o bolso.

\section{N2C6}

Tem mais ideologia vermelha comuna nas salas de aula que educação propriamente dita, por essa razão éque o país está uma bagunça total, o que vale é a ideologia e o corporativismo, o cabresto sindicalista impera, amor a Pátria inexiste...

\section{$\mathrm{N} 2 \mathrm{C} 7$}

Fora socialistas. Fora vermelhos. Precisamos de professores que trabalhem.

\section{$\mathrm{N} 2 \mathrm{C} 8$}

com a continuidade da greve voçês perderam o apoio da maioria da população paranaense, isso mostra que CUT PT -APP são todos joio do mesmo saco, se voces não querem trabalhar então se demitam, o problema é conseguir outro emprego com esse hitorico de......

\section{$\mathrm{N} 2 \mathrm{C} 10$}

Tirem essa CUT da greve que vocês serão mais ouvidos... Com o PT no meio vocês professores perderam toda a credibilidade!!!!! 
Nos sete comentários listados, seis referem-se à Notícia 2, que foi publicada após aproximadamente dois meses da deflagração da greve dos professores. Nos enunciados apresentados, a construção discursiva em torno do professor foi se acentuando de forma agressiva em relação ao objeto do discurso - o professor. Destaca-se o modo depreciativo como o objeto é referenciado (marxistas bardeneiros, ideologia vermelha, cabresto sindicalista, massa de manobra, socialistas, vermelhos). A linguagem mobilizada é extremamente icônica ao referenciar a cor vermelha que, no Brasil, é muitas vezes relacionada aos partidos políticos considerados de esquerda. No caso desses enunciados, é possível perceber uma associação entre o Partido dos Trabalhadores e o marxismo, socialismo e sindicalismo. Assim, no ponto de vista dos comentaristas, tudo que corresponde a uma visão de mundo diferenciada de uma perspectiva capitalista e liberal é tomado como um bloco homogêneo, ou seja, é visto como uma totalidade depreciada nos enunciados.

Nesses enunciados, mostrou-se também saliente a referência ao nacionalismo no comentário N2C6 (amor a Pátria inexiste...). Segundo Silva Filho (2013), o nacionalismo pode ser compreendido como ideologia unificadora, no início da República, que está ligado dialogicamente a outras ideologias: civismo, positivismo, higienismo e catolicismo. Trata-se de ideologias enformadas e oficiais que visam ao desenvolvimento de certo tipo de consciência, correspondente aos anseios das classes dominantes (SILVA FILHO, 2013).

Esses enunciados revelam como pano de fundo a problematização da própria identidade do professor e o que se espera dele historicamente. Para o comentarista, o papel desenvolvido pelo professor atualmente não corresponde à identidade docente constituída na historicidade da esfera escolar, que é aquela ligada à transmissão de conteúdos (Tem mais ideologia vermelha comuna nas salas de aula que educação propriamente dita) e a disseminação de uma visão patriótica a seus alunos. Essa voz parece conclamar o sentido de patriotismo reproduzido por muito tempo na esfera escolar (por essa razão é que o país está uma bagunça total, o que vale é a ideologia e o corporativismo, o cabresto sindicalista impera, amor a Pátria inexiste...). Assim, há um apagamento da identidade/categoria profissional que está no movimento grevista - o professor - e a sobreposição de uma identidade de professor responsável por contribuir para o desenvolvimento do cidadão a partir de uma suposta unidade nacional - a pátria. Nesse sentido, o discurso de nacionalismo é um modo de unificação das identidades, é uma forma de interditar o hibridismo, a mistura e restaurar as identidades purificadas (HALL, 2006, p. 52). É, pois, uma estratégia discursiva que tenta desqualificar a identidade profissional/institucional em favor de uma identidade nacional única e soberana.

Nessa construção discursiva, tendo como objeto de discurso o professor e seus posicionamentos em um evento específico, destacaram-se enunciados que o tomam como alguém descomprometido com a qualidade educacional, além do compromisso pedagógico com os estudantes e com a população.

\section{N2C9}

Lamento profundamente saber que não há nenhuma preocupação com os alunos. Até porque a maioria dos professores mantém seus filhos em escolas particulares, Pobres pais e alunos a depender desse pessoal: professores sem compromisso e desgoverno

\section{N2C4}

Para que a educação não fique refém dessa gente descompromissada, que olha só para o próprio umbigo e esquece dos alunos, deve ser privatizada. O Ensino Médio deve ser totalmente online, reduzindo em $90 \%$ seu custo de manutenção, permitindo a demissão dessa gentarada dependente do estado, que não honra sua obrigação e ainda se vê no direito de fazer a sociedade refém de seus caprichos e devaneios. Comprando esses serviços de empresas com qualidade superior ao ofertado pelos nossos professores, o estado e a sociedade pacificam em definitivo essa questão, livrando-se desses carrapatos que se julgam indispensáveis, reduzindo drasticamente os custos e melhorando a educação.

\section{N3C1}

Vamos trabalhar PTzada!!! Se um trabalhador ficar em casa por que quer aumento, ele não recebe e tem os dias descontados e pode perder o emprego se for configurado o abandono de função, Os professores não estão nem aí para 
os alunos que estão com o ano letivo ferrado, e ainda querem receber pelos dias $N A ̃ O$ trabalhados. A reivindicação dos professores é justa, mas essa greve já passou dos limites, estão pouco se lixando para as crianças.

O tom apreciativo, nesses enunciados, acentua-se pelo emprego de léxico relativo ao campo semântico do descompromisso (gente descompromissada/ professores sem compromisso), e também pelo emprego metafórico do termo carrapatos para se referir aos professores, associando-os a um parasita que se alimenta do sangue do hospedeiro, nesse caso, a sociedade. Verifica-se também o uso recorrente de expressões disfóricas que acentuam a conotação negativa como, por exemplo, gentarada dependente do estado, que não honra sua obrigação e ainda se vê no direito de fazer a sociedade refém de seus caprichos e devaneios.

Ao contrário dos enunciados que se ocupam do expediente de descorporificação do sujeito na estrutura político-social-ideológica, buscam-se elementos no ato ético do professor - na sua relação com seu outro ou outros (estudantes, pais e comunidade escolar). É a partir de sua vivência no ato de ser professor que ele é julgado como alguém sem compromisso com seus pares, pois deixar alunos sem aula implica afetar diretamente o aluno e a comunidade. Nessa estratégia discursiva, mobilizada para depreciar o objeto de discurso, os comentaristas tomam o professor como elemento gerador do movimento grevista, caprichoso e inconsequente, além de culpabilizá-lo de modo individual pelos problemas educacionais.

Nesse ponto da análise, vale destacar que a individualização e a responsabilização são estratégias há muito utilizada para a precarização e destruição da educação pública. Freitas $(2012)^{12}$, ao analisar o sistema educacional brasileiro contemporâneo, evidencia que a responsabilização do professor faz parte de uma agenda política neoliberal para a privatização da educação pública. Nesse contexto, "[...] o impacto desta política de submeter o professor a toda sorte de responsabilização e exposição pública começa a aparecer nas pesquisas sobre as percepções que professores, pais e alunos têm desta profissão" (MARKOW \& PIETERS, 2012 apud FREITAS, 2012, p. 394). A relação entre individualização e responsabilização do professor como uma estratégia do discurso em prol da privatização da educação se mostra nos enunciados em tela (Para que a educação não fique refém dessa gente descompromissada, que olha só para o próprio umbigo e esquece dos alunos, deve ser privatizada).

Dessa forma, há um discurso binário em que ora o professor é tomado como "massa de manobra” das estruturas políticoideológicas, ora é considerado totalmente senhor do seu fazer e a ele é atribuída a decisão de voltar a dar aula e não mais "prejudicar a população". Ambas as estratégias enunciativo-discursivas são operadoras do horizonte valorativo depreciativo em relação a esse objeto de discurso. Evidencia-se nesses enunciados uma dialogicidade interna do discurso que se constitui/se orienta nos discursos já ditos sobre o objeto (BAKHTIN, 2015).

Nessa reenunciação de discursos já-ditos, a mobilização por melhores condições de trabalho; pela melhoria da estrutura física e organizacional das escolas; pela melhoria dos processos de ensino-aprendizagem; pelo fortalecimento da categoria profissional docente não é tematizada, não é vista como uma posição de compromisso do professor com a comunidade escolar, mas sim como uma ação descomprometida.

Até aqui a análise explicitou a reenunciação de enunciados que apontam um horizonte depreciativo para o objeto de discurso - o professor e o movimento de greve. No entanto, em menor grau, os dados apresentaram vozes contrárias que manifestaram a defesa do professor; são enunciados que apontam um outro olhar, uma contrapalavra a esses já-ditos sobre o objeto de discurso, como o enunciado a seguir:

\section{N1C2}

Nos orgulha muito a iniciativa, a bravura e a persistência dos nobres professores no seu pleito diante de um governo irresponsável e mais ainda incompetente que temos nos últimos anos. Parabéns, e continuem na luta que acredito que será vencedora e em breve!! FORÇA NOBRES PROFESSORES!!!

\footnotetext{
${ }^{12}$ Neste texto, o pesquisador discute o projeto para educação de um grupo intitulado: "Reformadores empresariais da educação". Esse termo faz referência a uma coalizão entre políticos, mídia, empresários, empresas educacionais, institutos e fundações privadas e pesquisadores, alinhados com a ideia de que o modo de organizar a iniciativa privada é a proposta mais adequada para "consertar" a educação que as propostas feitas pelos educadores profissionais (FREITAS, 2012).
} 
Não é possível saber se o comentador é professor ou apoiador, contudo evidencia-se uma contrapalavra ao que estava sendo dito naquele espaço de interação discursiva. Em seu enunciado, o comentador apresenta um outro discurso, um outro modo para enunciar o professor e o movimento de greve, vendo-o como um lutador persistente, e responsabiliza a instância governamental pela crise instaurada. Esse enunciado não culpabiliza e individualiza o professor no contexto político-ideológico em tela e encerra seu projeto de dizer com um incentivo ao professor na sua luta por meio de um recurso multimodal, caracterizado pelo uso de letras maiúsculas: "FORÇA NOBRES PROFESSORES!!!".

\section{CONSIDERAÇÕES FINAIS}

A análise aqui apresentada aponta para os modos como o professor foi discursivizado em comentários que respondiam ativamente a notícias publicadas no jornalismo online acerca da greve dos professores da rede pública estadual no Paraná em 2015. Os dados evidenciaram a reenunciação depreciativa a respeito desse profissional tanto em relação à dimensão técnica da categoria, quanto humana na perspectiva ética do exercício de sua profissão.

O horizonte apreciativo se mostra, de modo mais saliente, na materialidade linguageira, nos usos estilísticos dos enunciados, sobretudo na escolha lexical dos autores dos enunciados, evidenciando o potencial sociocomunicativo desse gênero em acentuar valorativamente determinado projeto de dizer. Essa acentuação/tonalidade valorativa no material linguístico está, pois, intimamente ligada às condições de produção e circulação do gênero, cujo tema é uma "provocação" da empresa midiática ao leitor para que ele marque um posicionamento valorativo de convergência ou de divergência (ALVES FILHO; SANTOS, 2013) em relação aos assuntos em pauta (tema da enunciação).

Assim, este estudo evidenciou o potencial heurístico do percurso teórico-metodológico bakhtiniano para análises de discursos midiáticos contemporâneos, ressaltando o modo como o horizonte axiológico se materializa nos enunciados produzidos por sujeitos sócio e historicamente constituídos. Além disso, a análise empreendida evidencia as estratégias sociodiscursivas mobilizadas para discursivizar a identidade do professor nas instâncias jornalística e midiática. Concluímos, problematizando como esse discurso depreciativo sobre o professor e sua práxis, construído na tessitura histórica de uma multiplicidade de vozes, pode encontrar um lugar de brecha, de contradição, de reinvenção.

\section{REFERÊNCIAS}

ALVES FILHO, Francisco; SANTOS, E. Pereira. O tema da enunciação e o tema do gênero no comentário online. Revista Fórum Linguístico, Florianópolis, v. 10, n. 12, p. 78-90, 2013.

BAKHTIN, Mikhail M.; VOLOCHÍNOV, Valentin N. Marxismo e filosofia da linguagem: problemas fundamentais do método sociológico na ciência da linguagem. 11. ed. São Paulo: Hucitec, 2004 [1929].

BAKHTIN, Mikhail M. Questões de literatura e de estética - a teoria do romance. Tradução do russo por Aurora Fornoni Bernardini et al. São Paulo: UNESP; Hucitec, 1998 [1975].

Estética da criação verbal. Tradução do russo por Paulo Bezerra. 4. ed. São Paulo: Martins Fontes, 2003 [1979].

Problemas da poética de Dostoiévski. 4.ed. Trad. Paulo Bezerra. São Paulo: Forense-Universitária, 2008 [1963].

Teoria do romance I: a estilística. Tradução do russo por Paulo Bezerra. São Paulo: Editora 34, 2015 [1975].

Fórum linguistic., Florianópolis, v.13,n.3,p.1460-1475, jul./ set.2016 
BAKHTIN, Mikhail M. Para uma filosofia do ato responsável. Tradução aos cuidados de Valdemir Miotello e Carlos Alberto Faraco. São Carlos: Pedro \& João, 2010[1920].

CUNHA, Dóris de Arruda C. da. Reflexões sobre o ponto de vista e a construção discursiva de comentários de leitores na Web. Revista Investigações, Recife, v. 25, n. 2, p. 21-41, jul. 2012.

FARACO, Carlos Alberto. Ideologia. In: PAULA, Luciane; STAFUZZA, Grenissa (Org.). Círculo de Bakhtin: pensamento interacional. Campinas, SP: Mercado de Letras, 2013. Série Bakhtin: inclassificável, v.3.

GERALDI, João Wanderley. Ancoragens: estudos bakhtinianos. São Carlos (SP): Pedro \& João Editores, 2010.

KLEIMAN, Angela; VIANNA, Carolina; DE GRANDE, Paula. “Sem querer ir contra pessoas tão ilustres...”: construção e negociações identitárias do professor entre discursos de (des)legitimação. Scripta, Belo Horizonte, v. 17, n. 32, p. 173-194, 2013.

FREITAS, Luiz Carlos de. Os reformadores empresariais da educação: da desmoralização do magistério à destruição do sistema público de educação. Educação e Sociedade Campinas, v. 33, n. 119, p. 379-404, abr./jun. 2014.

HALL, Stuart. A identidade cultural na pós-modernidade. São Paulo: DP\&A, 2006.

GUIMARÃES, Anderson S.; QUEIJO, Maria Elizabeth da S. A arena discursiva das ruas e a condição pós-moderna: da manifestação à metacarnavalização. Revista Bakhtiniana: Revista de Estudos do Discurso, São Paulo, v. 10, n. 3, p.166-185, 2015.

RODRIGUES, Rosângela Hammes. A constituição e o funcionamento do gênero jornalístico artigo: cronotopo e dialogismo. 2001. 347 f. Tese (Doutorado) - Programa de Estudos Pós-Graduados em Linguística Aplicada e Estudos da Linguagem, Pontifícia Universidade Católica, São Paulo, 2001.

SILVA FILHO, Vidomar. A série didática Fontes: autoria e ato ético. 2013. 423 f. Tese (Doutorado) - Programa de Pós-Graduação em Linguística, Universidade Federal de Santa Catarina, Florianópolis, 2013.

SILVA, Nívea Rohling da. O horizonte valorativo do gênero entrevista pingue-pongue: o papel social do entrevistado. Trabalhos em Linguística Aplicada, Campinas, v. 49, p. 87-99, jan./jun. 2010.

VOLOCHÍNOV, Valentin N. A construção da Enunciação e outros ensaios. São Carlos (SP): Pedro \& João Editores, 2013 [1930]. 